\title{
Correction to "Family Medicine Patients' Use of the Internet for Health Information: A MetroNet Study"
}

In the abovementioned article (Schwartz KL, Roe T, Northrup J, Meza J, Seifeldin R, Neale AV. J Am Board Fam Med. 2006;19(1):39-45), in Table 1, the 2-sided $P$ value for the association of sex by respondent type should be .100 (not .063 as printed). We apologize for the error, and we regret any confusion or inconvenience it may have caused. (doi: 10.3122/jabfm.2008.05.080133.) 